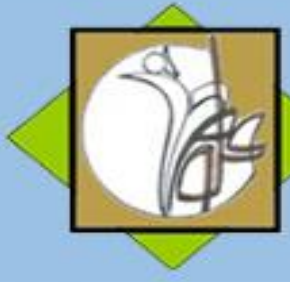

Research Article

\title{
The Comparison and Relationship between Cognitive and Motor Function in Elderly with and without Falling Experience
}

\author{
Sima Ramesh ${ }^{1}$, Elaheh Azadian²,Mahdi Majlesi ${ }^{3}$
}

1. Sima Ramesh, (MSc Student) Islamic Azad University, Hamedan Branch, Hamedan, Iran.

2. Elaheh Azadian, (Ph. D) Islamic Azad University, Hamedan Branch, Hamedan, Iran.

3. Mahdi Majlesi, (Ph. D) Islamic Azad University, Hamedan Branch, Hamedan, Iran.

\section{ARTICLE INFO}

Received October 2018

Accepted November 2018

\section{KEYWORDS:}

Elderly, Falling,

Cognitive Function,

Balance

\section{CITE:}

Ramesh, Azadian, Majlesi, The Comparison and Relationship between Cognitive and Motor Function in Elderly with and without Falling Experience, Research in Sport Management \& Motor Behavior, 2020: 10(20): $138-150$

\section{ABSTRACT}

The evaluation of cognitive and motor performance can lead to a recognition of the risk factors associated with falling. The aim of this study was to compare cognitive and motor functions in elderly with and without experience of falling. In so doing, 60 elderly with and without falling experience voluntarily participated in this study. Mini Mental examination Test, working memory capacity test, reaction time, inhibition test, Berg balance test, tandem balance test, 6-minute walking test and balance confidence test were all administered to the groups. To analyze the data thus obtained, and to examine the relationship between the variables for estimated fall, independent samples t-test and regression analysis were run. The significance level was considered as $p<0.05$. The results showed that elderly people with fall experience had a weaker cognitive and balance-maintenance performance than those without such experience $(p<0.05)$. The results of correlation and regression analyses indicated that Berg balance test, tandem, inhibition and MMSE had the strongest relationship with falling. Based on these results, it can be claimed that fall in elderly is associated with poor balance as well as cognitive decline. Age is one of the predictors of falling, and about $25 \%$ of motor activities are related to cognitive capacities. 


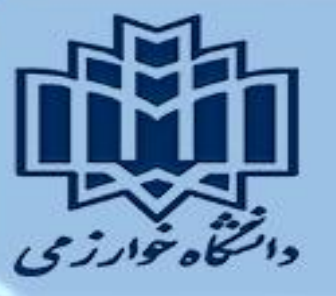

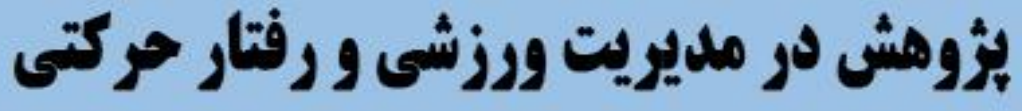

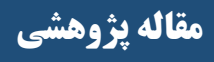

\section{مقايسه و رابطه بين عملكرد شناختى و حر كتى در سالمندان با و بدون تجربه افتادن

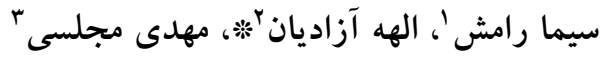

ا. دانشجوى كارشناسى ارشد رفتار حركتى، كروه تربيت بدنى و علوم ورزشى، دانشكده علوم انسانى، دانشگاه آزاد اسلامى واحد همدان، همدان، ايران.

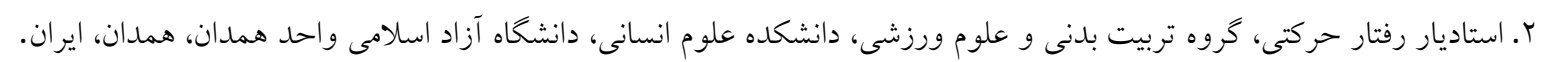

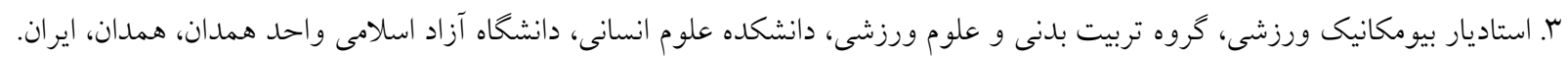

\begin{tabular}{|c|c|}
\hline 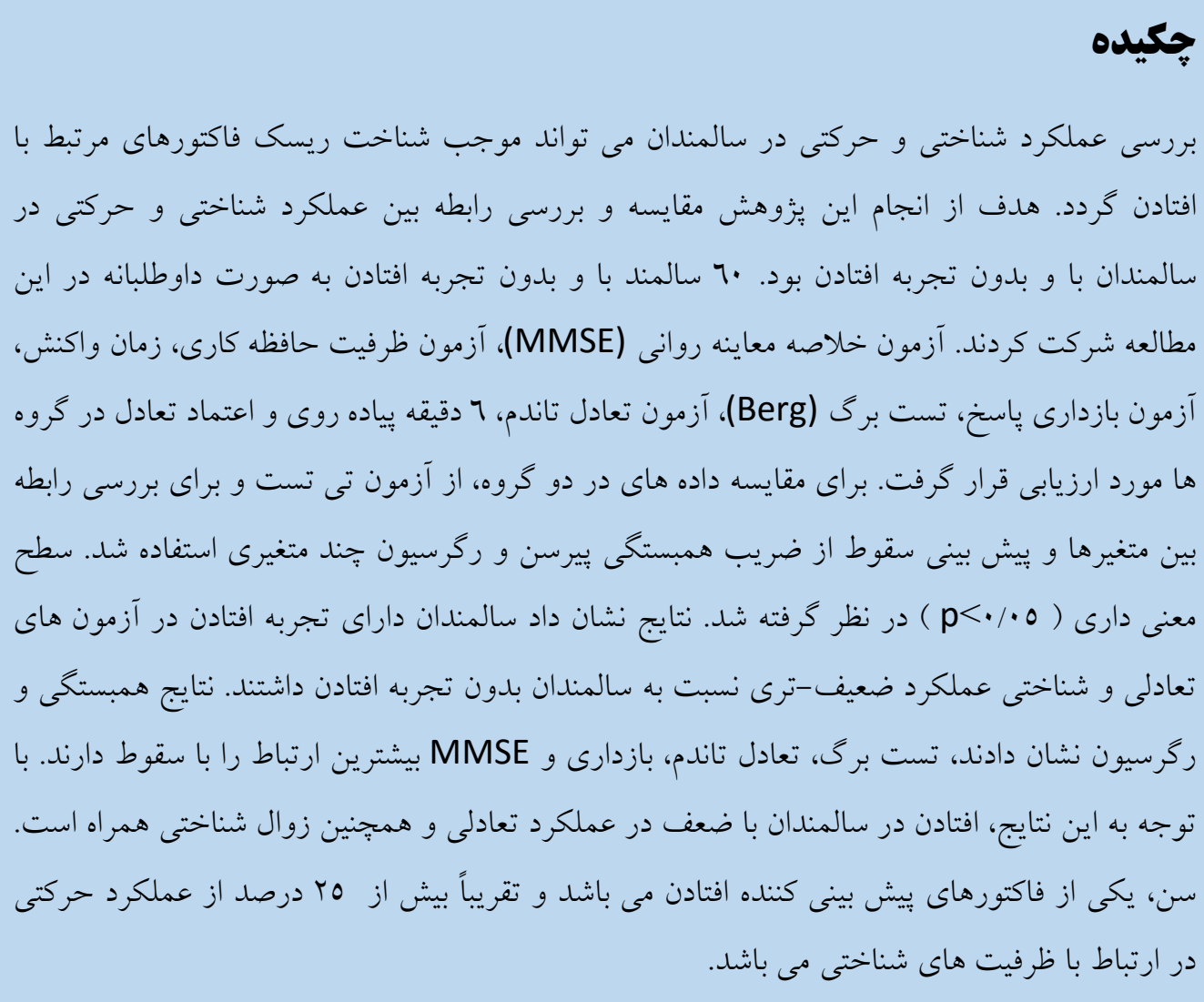 & 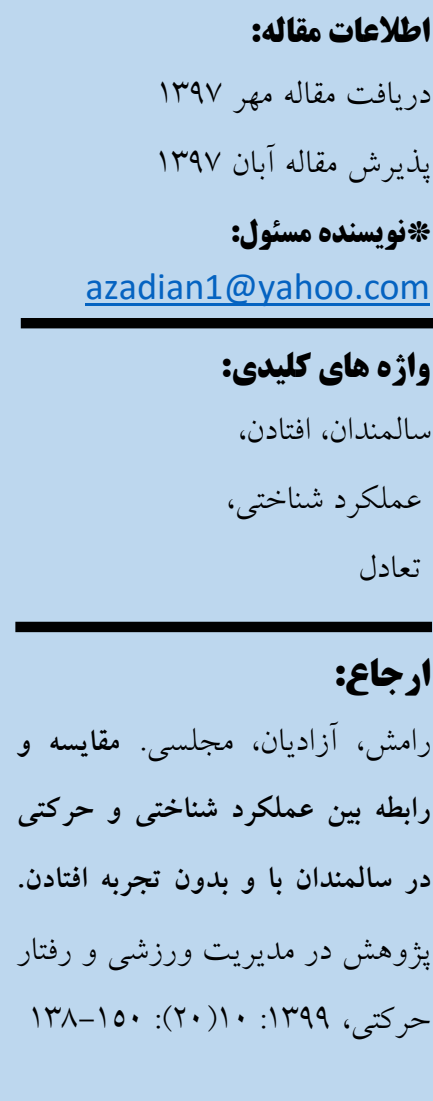 \\
\hline
\end{tabular}




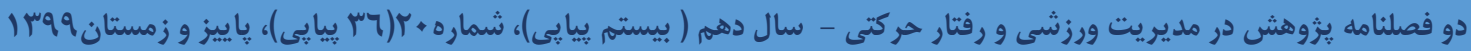

مقلدمه

افزايش سن بهطور طبيعى با تغيير در بسيارى از عملكردهاى حسى و حركتى همراه مىباشد. تغييرات ساختارى و عملكردى در سيستمهاى حسى، حركتى و همجنين در سيستم عصبى مركزى عصبى (1)، موجب اختلال در تعادل و راه رفتن مىشود كه در نهايت منجر به كاهش فعاليتهاى روزمره در سالمندان خواهد شد (ع-Y). همه اين عوامل مىتواند موجب جلو گيرى از توليد نيروى كافى، عدم واكنش سريع به آشفتخىهاى قامتى و نهايتاً منجر به افتادن كردد (0, 7). تغيير در حواس و عملكرد حركتى و فرآيندهاى مركزى آن، تنها عامل مرتبط با آسيب تعادلى ناشى از كذر سن نيستند، بلكه زوال در فر آيندهاى شناختى نيز فاكتور مهمى محسوب مى شود (V)). مطالعات نشان دادهاند كه افتادن در سالمندان با بيمارىهاى مزمن، ضعف اندام تحتانى، ضعف عملكرد شناختى، سابقه افتادن، مؤنث بودن و ترس از افتادن در ارتباط است (^). ارتباط بين عملكرد شناختى با تحرى فرد را مى توان در بيماران داراى آسيب شناختى مشاهده كرد. در بيماران آلزايمر، ميزان سقوط با بيشرفت بيمارى، افزايش مى يابد (9). در اين بيماران، تغيير بذيرى در راه رفتن هنگام اجراى تكاليف دو كانه مثل شمارش معكوس (••(1) يا تكرار اعداد تصادفى (11) افزايش مى يابد. همجنين ارتباط بين عملكردهاى شناختى و كاهش سرعت راه رفتن در سالمندان با آسيب شناختى متوسط (Y I)، زوال عقلى'(r) و هيدروسفالى ناشناخته (ع)، كزارش شده است.

افزايش سن با كاهش در توده مغز، كاهش ضخامت قشر مغز و زوال كاركردهاى اجر ايى بكه توسط قشر بيش بيشانى كنترل مى شود، ارتباط دارد. كاركردهاى اجر ايى شامل مجموعهاى از مر احل شناختى است كه كنترل، هماهنكى، سازماندهى و حفظ بقيه توانايى هاى شناختى را بر عهله دارد (ع)(). در ميان انواع مختلف عملكردهاى شناختى، احتمالاً كاركردهاى اجرايى نقش ضرورى و مهمى در توانايى راه رفتن و حفظ تعادل همزمان با اجراى تكليف ديكر و يا در تكرار سقوط دارد (010). كاهش در ظرفيت كاركرد اجرايى با عملكرد لوبّ بيشانى مرتبط مى گردد كه منجر به افزايش زمان واكنش، كاهش عملكرد تكليف دو گانه، كاهش ظرفيت توجه و در نتيجه افزايش تعداد سقوط در سال خو اهد شد ( (آ-7 (1). مطالعه هرمان و همكاران (•(Y. (Y) نشان داد سالمندان سالمى كه داراى عملكرد ضعيف در كاركرد اجرايى هستند ولى تجربه سقوط ندارند، r سال يّ از اندازه گيرى دجّار سقوط شدهاند (Yr). سالمندانى كه كاهش در كاركرد اجرايى را تجربه

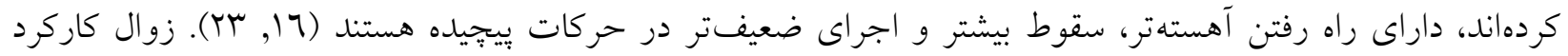
اجر ايى احتمالاً در تقليل مكانيسمهاى جبرانى در ياسخ به تغييرات مرتبط با سن در راه رفتن و تعادل، اختلال در تعادل و راه رفتن (Y (Y) و افزايش خطر سقوط (17) سهم دارد. اين موضوع نشان مىدهد كه ارزيابى كاركرد اجرايى مىتواند

\footnotetext{
1 .Dementia
}

2 . Executive function

https://jrsm.khu.ac.ir/ 


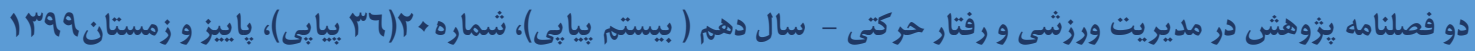

بيشخوى خوبى براى سقوط باشد (1) IV). ممكن است كاركرد اجر ايیى يك نشانكر زيستى در توانيى هاى شناختى يا اندوخته مغز و انعطاف يُذيرى لازم براى كاهش تكرار سقوط باشد (YT).

در سالهاى اخير ارتباط بين سطوح بالاى عملكردهاى شناختى و اختلال در راه رفتن مورد توجه بوده است. در اين مطالعات عوامل تأثير كذار بر سقوط مورد بررسى قرار گرفته است (Y0). هدف از اين مطالعه مقايسه فاكتورهاى شناختى و عملكردى در دو گروه با و بدون تجربه افتادن و همجنين بررسى و مقايسه عوامل شناختى و تعادلى در بيشبينى سقوط خواهل بود.

\section{روش}

جامعه آمارى يزوهش حاضر شامل مردان سالمند ساكن شهر همدان بودند. از بين اين افراد ·ـ سالمند بدون سابقه افتادن و • •بالمند داراى سابقه سقوط بهصورت هدفمند در اين يزوهش شركت كردند. تعداد نمونه آمارى با نرمافزار

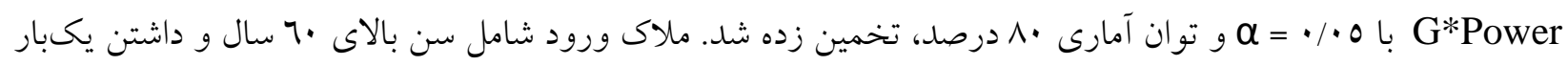
سابقه افتادن در يكى سال كذشته، براى گروه داراى سابقه سقوط و نداشتن سابقه افتادن براى گروه كنترل بود. ملاك خروج

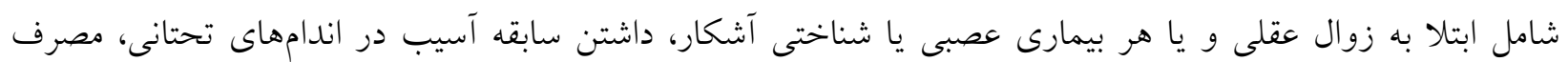
داروهايى كه بر عملكرد سيستم عصبى و يا حركتى تأثير گذار باشد، بود.

در اين يزوهش كاركردهاى اجرايى شامل حافظه كارى، توانايى بازدارى ياسخ و زمان واكنش مورد سنجش قرار گرفتند (Yך). همجنين پيرسشنامه مختصر معاينه روانى (MMSE) براى ارزيابى زوال عقل در شركت كنند كان مورد استفاده قرار كرفت (YV). براى سنجش عملكرد حركتى افراد از آزمون برى (Berg)، شش دقيقه بيادهروى و برسشنامه اعتماد تعادل استفاده گرديد (YN) و همجينين تعادل ايستا در حالت ايستادن تاندم مورد اندازهيرى قرار كرفت (YV).

براى ارزيابى حافظهكارى از سنجش فراخناى حافظه ارقام كه يكى از خرده آزمونهاى آزمون هوش وكسلر مىباشد و نرمافزار سنجش حافظه كارى، ساخت شركت روان تجهيز سينا، استفاده شد. اين آزمون در دو بخش، تكرار روبهجلو اربـ ارقام و تكرار معكوس ارقام، بهطور جداگانه و بهصورت شنيدارى اجرا مىشود. در هر دو آزمون ابتدا اعداد خوانده مىشود و سبس فرد بايد، اعداد را به ترتيب، بيان كند. زنجيره اعداد در بخش تكرار ارقام روبه جلو از r تا V عدد در هر زنجيره و در بخش معكوس از Y تا V عدد در هر زنجيره مىباشد. براى هر زنجيره از اعداد دو كوشش به شركت كننده ارائه مىشود. در صورت موفقيت يا شكست در كوشش اول، كوشش دوم ارائه مىشود. هر كاه شركت كننده در هر دو كوشش مربوط رط به يكى زنجيره معين، ناموفق باشد، آزمون متوقف مى گردد. به هر سؤال نمره دو، يك يا صفر بدين شرح داده مىشود؛

3 . Mini Mental State Examination

https://jrsm.khu.ac.ir/ 


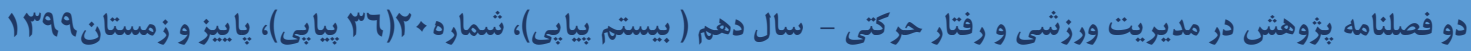

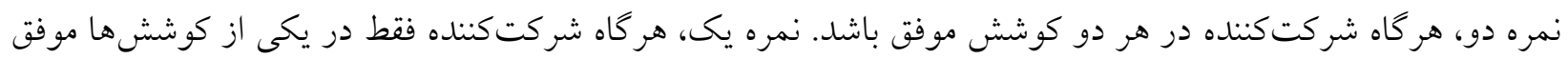
باشد. نمره صفر، هر كاه شركت كننده در هر دو كوشش ناموفق باشد (TV).

براى سنجش توانايى بازدارى أز آزمون Stop Signal Task استفاده شد كه نرمافزار آن توسط شركت روان تجهيز سينا ساخته شده است. در اين آزمون فرد بايد با سرعت به يك محرى ديدارى يّاسخ دهد. در برخى از تلاشها، علاوه بر

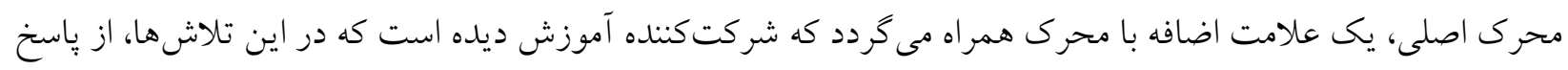
اجتناب كند. در اين يزوهش علامت ج و ـ ؟بهنوان محرك ارائه مىشود، و ياسخ كليدهاى جهتنما در صفحه كليد كاميوتر بود. علامت اضافهاى كه همراه با تعدادى از محركها ارائه مى كرديد صداى "بيب" بود. در صورت همراه شدن صدا، فرد نبايد هيج كدام از كليدها را فشار دهد (YV).

براى اندازه كيرى زمان واكنش از دستخاه زمان واكنش ERT (ساخت شركت دانش سالار ايرانيان، تهران، ايران) استفاده شد. در اين مطالعه زمان واكنش ساده در سه وضعيت نشسته، ايستاده و در حال راه رفتن ثبت گرديد. همجنين زمان واكنش انتخابى در حالت نشسته و با دو محرك ديدارى، جهت جبٍ يا راست، و ياسخ فشار دادن كليد با دست راست يا

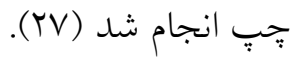
تست تعادلى برى براى اندازه گيرى تعادل كاركردى در سالمندان طراحى شده و داراى عا آيتم مىباشد. نمره هر آيتم بين صفر تا ع مىباشد و بنابراين امتيازات از 07 تا صفر متغير است. آيتمها عبارتند از: () بلند شدن از حالت نشسته، ب) ايستادن بدون حمايت، ץ) نشستن روى يكى صندلى بلدون يشتى، ع) نشستن از حالت ايستاده، 0) انتقال از يك جهار بايه به صندلى، 7) ايستادن بدون حمايت با جُشمان بسته، V) ايستادن بدون حمايت با پاهاى جفت شده، ^) كشش دستها به جلو در حالت ايستاده، 9) برداشتن يك شىء از زمين از حالت ايستاده، · (1) جֶرخش به سمت شانه جֶٍ و راست براى

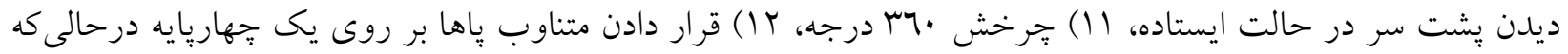
فرد بدون حمايت ايستاده است، ஈ|) ايستادن بدون حمايت وقتى يك پِا جلوى ياى ديخر قرار دارد و ع () ايستادن روى يكى با (rq).

آزمون خلاصه معاينه روانى (MMSE) يرسشنامه كوتاهى است كه به دليل روايى و پِايايى عالى آن بركاربردترين ابزار

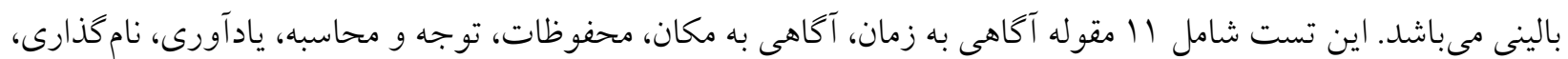
تكرار، درك مطلب، خواندن، نوشتن و ترسيم كردن، مىباشد (•r). بايايى (به روش دونيمه كردن)، ويزگى و حساسيت

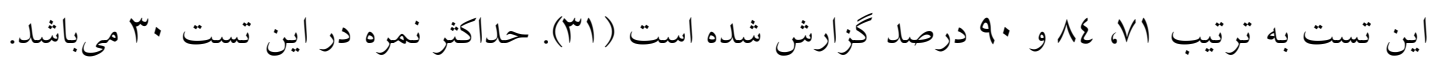

\footnotetext{
4 .Stop Signal Task

5 . Berg Balance Test

6. Min Mental State Examination
}

https://jrsm.khu.ac.ir/ 


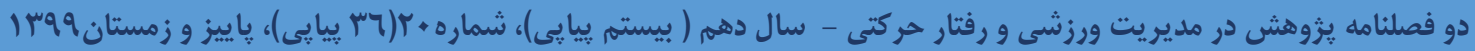

آزمون شش دقيقه بيادهروى جهت بررسى آمادگى جسمانى سالمندان طراحى گرديده است. مسافت طى شده در اين

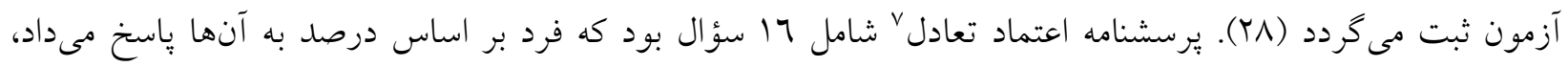
سبس درصد داده شده به سؤالها با هم جمع شده و بر 17 تقسيم مىشود (YN). در اين يزوهش حركات مركز فشار بدن (CoP) براى سنجش تعادل ايستا با استفاده از دستخاه تخته نيروى كيستلر (Kistler 9281EA, Winterthur, Switzerland) اطلاعات مربوط به حركات CoP يس از آمادگى فرد بر روى دستخاه تخته نيرو آغاز شود. بارامترهايى كه از اين طريق جمع آورى مىشوند شامل انحرافات و نوسانات CoP در دو سطح AP, ML مىباشد. تست تعادل ايستا شامل ايستادن

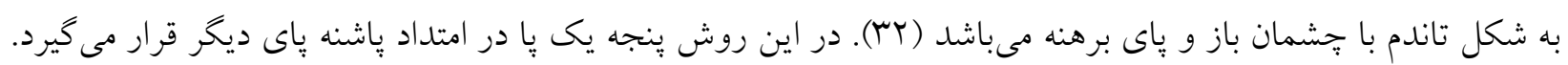
در اين آزمون بِاى غالب فرد در يشت يّاى ديخر قرار مى گيرد.

نرمال بودن توزيع دادهها با استفاده از آزمون شاييروويلك مورد بررسى قرار گرفت. براى مقايسه متغيرهاى مورد بررسى در دو گروه از آزمون تى تست مستقل و براى بررسى رابطه بين متغيرهاى شناختى و حركتى از آزمون همبستخى بيرسون

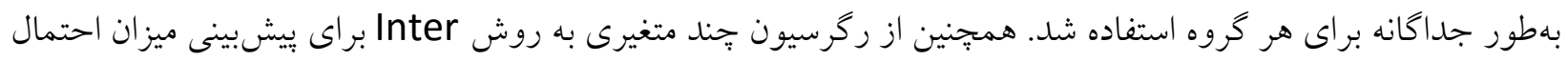

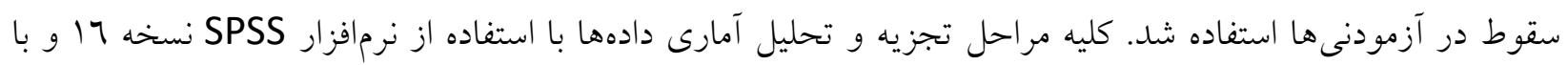
سطح معنادارى 0 •/ > انجام كرديد.

\section{يافتهما}

اطلاعات دمو گرافيك آزمودنى ها به تفكيك براى هر گروه در جدول آورده شده است. همانطور كه در جدول مشاهده مى شود دو گروه از لحاظ دامنه سنى داراى اختلاف معنى دارى بودند؛ اما در بقيه مشخصات اختلاف معنىدارى مشاهده

7 . Balance Confidence Questionary

https://jrsm.khu.ac.ir/ 


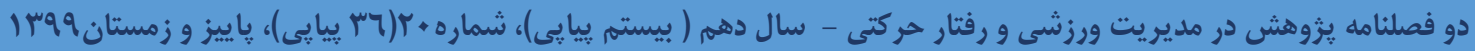

جدول ا. ويزگى هاى دمو كرافيك شركت كندكان در كروهها

\begin{tabular}{|c|c|c|c|c|c|c|c|}
\hline \multirow[b]{3}{*}{$\operatorname{Sig}(t)$} & \multicolumn{6}{|c|}{ كروههاى يززوهش } & \\
\hline & \multicolumn{3}{|c|}{ با تجربه سقوط } & \multicolumn{3}{|c|}{ بدون تجربه سقوط } & \\
\hline & SE & SD & ميانخين & SE & SD & ميانخين & \\
\hline$\cdot / \cdot 1(r / V I)^{*}$ & $\cdot / 9 V$ & $0 / \Gamma$. & Vo/Vr & $\cdot / \Upsilon \wedge$ & $r / \cdot q$ & $V I / A V$ & سن (سال) \\
\hline.$/ .0 \wedge(1 / 9 r)$ & $\cdot / \cdot 1$ & $\cdot 1 \cdot 7$ & $1 / 7 \varepsilon$ & $\cdot 1 \cdots 9$ & .1 .0 & $1 / 7 V$ & قد (متر) \\
\hline$\cdot / \Gamma \varepsilon(\cdot / 97)$ & $r / v q$ & $10 / \mu$. & $v \cdot / v q$ & $1 / 90$ & $1 . / 77$ & TV/or & وزن (كيلوگرم) \\
\hline$\cdot / \cdot V(I / \wedge r)$ & $\cdot / 9 \varepsilon$ & $0 / 17$ & $r Y / I r$ &.$/ 01$ & $r / 19$ & $r \varepsilon / 11$ & BMI \\
\hline
\end{tabular}

نكته: BMI= شاخص جرم بلدن(وزن / مجذور قد)، SD= انحراف /ستاندارد، SE= انحراف معيار

نتايج تحليل دادهاى مربوط به متغيرهاى ارزيابى شده در اين يزوهش در جدول r نشان داده شده است. نتايج مربوط به تحليل نمرات زمان واكنش نشان داد كه اختلاف بين دو كروه در وضعيت نشسته و ايستاده معنى دار بوده، درحالى كه زمان و اكنش در حين راه رفتن و هم:جنين زمان واكنش انتخابى در دو گروه مشابه بود و اختلاف معنىدارى مشاهده نشد (0٪/ > p همجنين اختلاف نمره كسب شده كروهها در هر دو خرده مقياس آزمون وكسلر نيز معنى دار نبود (0 • > > p). اما نمر ات كسب شده در متغيرهاى مربوط به آزمون بازدارى معنى دار گزارش گرديد (0 •/• > p). در اين آزمون گروه داراى

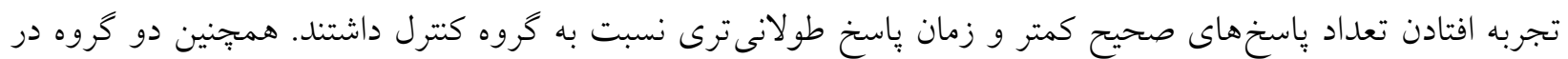
آزمون تعادل تاندم در تمام متغيرها داراى اختلاف معنى دارى بودند (0 • • > p). 
جدول. r. مقايسه نمرات آزمونها در دو گروه با و بدون سابقه افتادن

\begin{tabular}{|c|c|c|c|c|}
\hline $\mathbf{t}$ & Sig. & Fall & No fall & ريسك فاكتور \\
\hline \multirow[t]{2}{*}{$r / N I$} & $\cdot / \cdot 1$ & VO/Ar $\left(0 / r^{\prime}\right)$ & $V I / A V(Y / .9)$ & سن \\
\hline & & & & زمان واكنش \\
\hline$r / 7 r$ &.$/ \cdot 11$ & $V 7 r / \varepsilon q(\Gamma \cdot 0 / 1 \Lambda)$ & $O V \cdot / T_{O}\left(Y^{\prime} \cdot / 0 \mathrm{~N}\right)$ & نشسته \\
\hline$\Gamma / \Lambda$ & $\cdot \cdots r$ & $099 / .0(1 \mathrm{~V} / / 70)$ & $\varepsilon 07 / 9 \varepsilon(\mid V \varepsilon / .0)$ & ايستاده \\
\hline $1 / 94$ &.$/ \cdot 7$ & $777 / \varepsilon q(\mu \mid \varepsilon / \Gamma \varepsilon)$ & OrI/IT (YYY/YT) & راه رفتن \\
\hline \multirow[t]{2}{*}{$1 / 11$} & $\cdot / T V$ & $\vee \vee I / \Gamma \wedge(Y \vee \neg / \wedge q)$ & 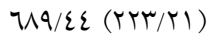 & انتخابى \\
\hline & & & & بازدارى \\
\hline $0 / \cdot \varepsilon$ & $\cdot / \cdots$ & 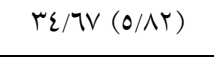 & $\varepsilon r / \cdot V(V / \cdot r)$ & ياسخ صحيح \\
\hline O/YT & $\cdot / \cdots$ & $\mid r / \varepsilon V(r / q T)$ & $0 / 9 \Psi(0 / 7 \cdot)$ & هِاسخ اشتباه \\
\hline$r / 01$ & $.1 \cdot 10$ & r/AV (ז/M & $1 / \cdot(Y / Y q)$ & بى ياسخ \\
\hline \multirow[t]{2}{*}{$T / T V$} & $\cdot / \cdot T V$ & $1 \cdot 1 N / 1(Y K N / I)$ & $\Lambda V V / \Lambda(Y O \cdot / V O)$ & زمان \\
\hline & & & & وكسلر \\
\hline . / Vo & $\cdot / 27$ & $r / \varepsilon V(\cdot / 9 V)$ & $r / 7 V(1 / \cdot 9)$ & شمارش روبهجلو \\
\hline \multirow[t]{2}{*}{$\cdot / \varepsilon \mid$} & $\cdot / 7 \Lambda$ & $T / M T(1 / 07)$ & $T / \Sigma V(\cdot / A T)$ & شمارش معكوس \\
\hline & & & & تعادل \\
\hline$r / 9 T$ & $\cdot \cdots$ & $\Lambda / T Y(Y / \cdot T)$ & $0 / 0 \varepsilon(r / r q)$ & انحر اف AP \\
\hline$r / 10$ & $\cdot \cdots r$ & T/M $(1 / 1 Y)$ & $1 / 01(\cdot / 1 \mathrm{~A})$ & انحراف ML \\
\hline$r / \varepsilon r$ & $\cdot / \cdot r$ & $\cdot / 9 Y(\cdot N 1)$ & $\cdot / 09(\cdot / 11)$ & نوسانات AP \\
\hline$r / v \varepsilon$ & $\cdot / \cdot 1$ & $1 / r \cdot(\cdot / r q)$ & $\cdot / \wedge 9(\cdot / \pi)$ & نوسانات ML \\
\hline $0 / r$ & $\cdot / \cdots$ & $r \mu / r(Y / T O)$ & $r T / r(Y / I I)$ & MMSE \\
\hline 11/R & $\cdot / \cdots$ & $\varepsilon 1 / \Gamma(\Gamma / N Y)$ & $\varepsilon 9 / Y(1 / \cdot 7)$ & Berg \\
\hline$r / \wedge q$ & $\cdot / \cdots$ & $\Lambda Y / \varepsilon\rceil(\Lambda / \backslash \varepsilon)$ & 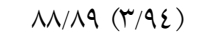 & اعتماد تعادل \\
\hline
\end{tabular}

براى بررسى قدرت بيشكويى متغيرها، از رگرسيون جند متغيرى به روش Enter استفاده گرديد. نتايج اين آزمون نشان

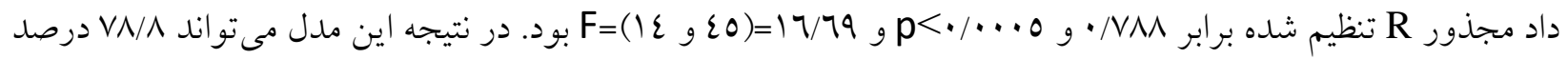
واريانس را توجيه كند. بين متغيرهاى مورد بررسى آزمون برى با ضريب بتاى استاندارد شده

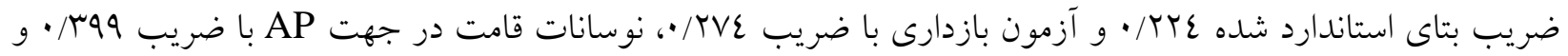

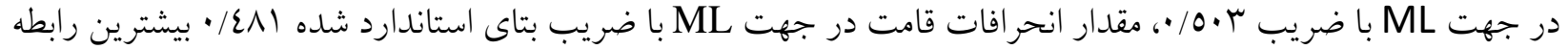

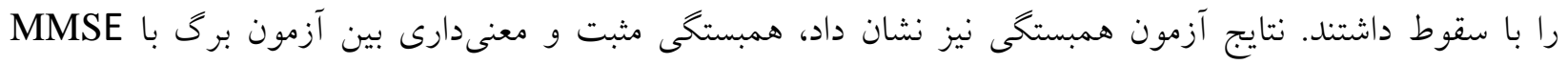

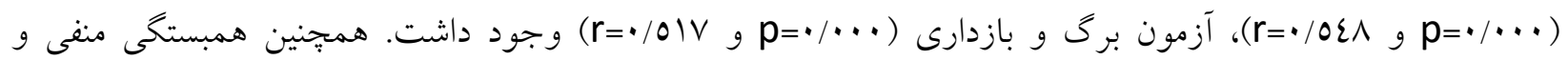




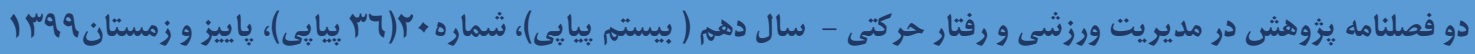

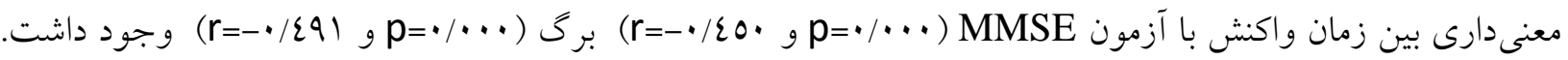
در بقيه متغيرها نيز همبستكى معنى دار و در سطح متوسط بودند.

\section{بحث و نتيجه تيرى}

نتايج يزوهش حاضر در راستاى كزارشهايى است كه در مورد تعادل و نقش فعاليتهاى شناختى در كنترل قامت سالمندان انجام يذيرفته است. يافته هاى اين مطالعه نشان داد، سالمندان داراى تجربه سقوط در ظرفيت شناختى خود دجّار اختلال مىباشند. تحقيقات كذشته نشان دادهاند كه كسب نمره يايينتر از بَ در آزمون MMSE، نشاندهنده زوال عقلى متوسط مىباشد؛ با توجه به نتايج بهدستآمده در اين يزوهش افراد داراى تجربه سقوط در مرز اين محدوده قرار دارند. نتايج مطالعه درويتر و همكاران (Y.IV) همسو با اين يافته نشان داد كه كاهش نمره MMSE در افرادى كه تجربه افتادن

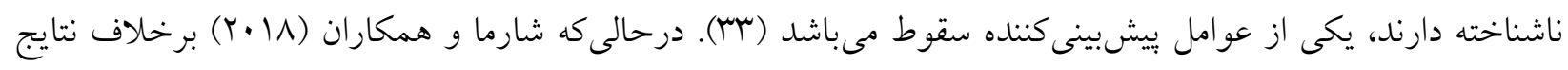
اين يزوهش كزارش كردند كه نمره MMSE در بيشبينى سقوط مؤثر نيست (عץ). بنابراين مىتوان نتيجه كرفت كه تجربه افتادن مىتواند يكى از نشانهاى تشخيص زوال عقل، در سالمندان باشد.

يكى از مهمترين فاكتورهاى مورد بررسى از عملكرد شناختى سرعت يردازش اطلاعات است (†0). بررسى زمان واكنش به محرك صوتى در شركت كنند گان اين يزوهش نشان داد كه سرعت پِاسخ در سالمندان سقوط كرده كمتر از سالمندان

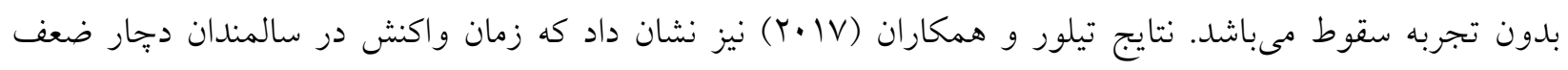
شناختى كمتر از ديخر سالمندان مىباشد (Tr) و بنابراين مىتواند بهعنوان يك ريسك فاكتور در سقوط معرفى كردد. توانايى بازدارى ياسخ، بهعنوان مهمترين جزء كاركردهاى اجرايى، شناخته شده است. بدين معنى كه فرد علاوه بر توانيى

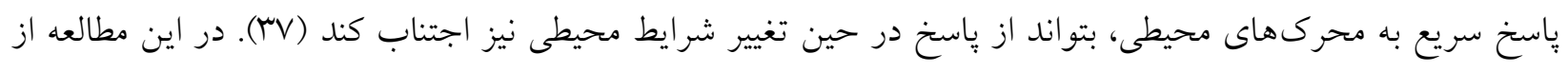

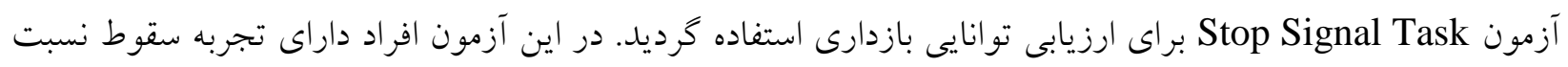
به گروه كتترل تعداد ياسخهاى صحيح كمترى را كسب نمودند، درحالى كه زمان بيشترى را صرف اجر ایى اين آزمون كرده

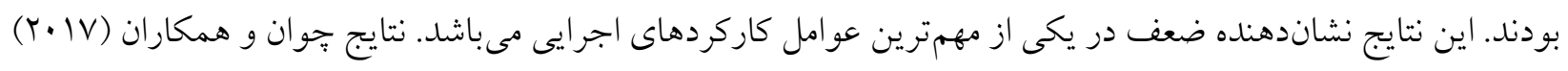

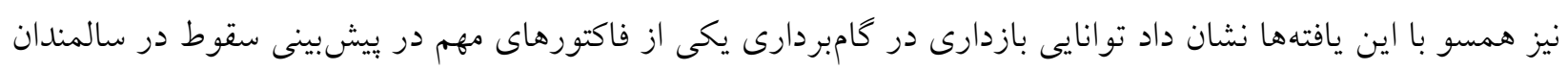

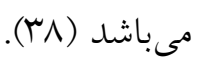

نتايج آزمون برگ، آزمون تعادل تاندم و آزمون 7 دقيقه ييادهروى نيز نشان دادند عملكرد تعادلى در سالمندان داراى سابقه افتادن بهطور معنى دارى ضعيفتر از كروه كنترل (بدون تجربه سقوط) بوده است. نتايج مطالعات زيادى همسو با يافته هاى اين يزوهش نشان دادند كه كنترل قامت در سالمندان داراى تجربه افتادن ضعيفتر از سالمندان بدون تجربه سقوط مىباشند

.$(r q-\varepsilon r)$

https://jrsm.khu.ac.ir/ 


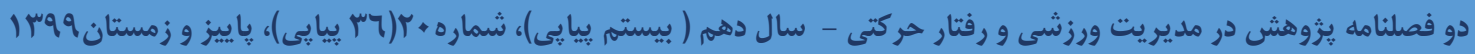

نتايج آزمون رگرسيون نشان داد اندازهيرى نوسانات بيشتر از انحرافات، مىتواند در شناسايى افراد دارى خطر افتادن كمك كند. در اين مطالعه نوسانات قامت در جهت ML با ضريب بتاى بيشتر ارتباط زيادى با ريسك سقوط داشت. افزايش نوسانات در جهت ML ناشى از كاهش تون عضلات آبداكتور / آداكتور ران مىباشد (ع)). همجنين نوسانات نسبت به انحر افات قامت ارتباط بيشترى با ويزگى هاى كنترل حركتى در سيستم عصبى مركزى دارد، درحالى كه انحراف قامت ممكن است به علت وضعيت ساختارى بدن باشد، به همين علت در تحقيقات كنترل حركتى از نوسانات قامت براى ارزيابى تعادل و كنترل قامت استفاده مى گردد.

آزمون برى يكى از مهمترين آزمونها براى بيشبينى خطر افتادن در سالمندان مىباشد. نتايج رگرسيون كه از متغيرهاى مورد بررسى در اين يزوهش بهدست آمد، نشان داد كه آزمون تعادلى تاندم داراى بيشترين ارتباط با آزمون برى بونى بوده و مىتواند بهعنوان يكى آزمون بيشگُى مؤثر و راحت در انتخاب سالمندانى كه داراى خطر سقوط هستند كمك كننده باشد. آزمون MMSE نيز نسبت به ديخر آزمونهاى شناختى ارتباط بيشترى با عملكرد حركتى نشان داد. درحالى كه آزمون Stop Signal Task يزٔوهش بيان كردند، بالا رفتن سن يكى از نشانه هاى مهم در بيشبينى افتادن مىباشد. مطالعه شارما و همكاران (N (Y) نيز نشان داد كه زوال عقلى، سابقه افتادن مجدد، داشتن مشكلات جسمانى و سن بالاى •م سال مىتوانند بهعنوان بيشخو هاى سقوط معرفى گردند (عَr). بررسى ضريب تشخيص در اين تحقيق نشان داد كه بين عملكرد شناختى و تعادلى حدود VV درصد رابطه وجود دارد، بنابراين ممكن است بتوان نتيجه كرفت كه با تمرينات شناختى، عملكرد حركتى نيز بهبود مى يابد و بالعكس. در اين يزوهش فقط از مردان سالمند استفاده شد كه از جمله محدوديتهاى ئزوهش حاضر

بشمار مى آيد.

با توجه به نتايج يزوهش حاضر افرادى كه داراى ضعف تعادلى هستند و يا در مراحل متوسط زوال عقلى مىباشند، بهعنوان افراد يرخطر براى افتادن محسوب مى شوند. آزمون برگ، آزمون تعادل تاندم و آزمون MMSE در اين مطالعه بيشترين ارتباط را با ريسك سقوط داشتند. با استفاده از اين آزمونها بهويزه آزمون تعادل تاندم كه بهراحتى قابل اجرا است، مى توان سالمندان داراى خطر افتادن را شناسايى كرد. با توجه به اين نتايج بيشنهاد مى گردد كه افراد بالاى •V سال، افرادى كه سابقه سقوط دارند، و يا افر ادى كه دجار ضعف تعادلى هستند، براى بهبود عملكرد شناختى، از تمرينات شناختى كه در سالهاى اخير مورد توجه قرار گرفته است استفاده نمايند. 
1. Wollesen B, Voelcker-Rehage C. Training effects on motor-cognitive dual-task performance in older adults. European Review of Aging and Physical Activity. 2014:1-20.

2. Faulkner JA, Larkin LM, Claflin DR, Brooks SV. Age related changes in the structure and function of skeletal muscles. Clinical and Experimental Pharmacology and Physiology. 2007;34(11):1091-6.

3. Barbieri G, Gissot A-S, Pérennou D. Ageing of the postural vertical. Age. 2010;32(1):51-60.

4. Borel L, Alescio-Lautier B. Posture and cognition in the elderly: Interaction and contribution to the rehabilitation strategies. Neurophysiologie Clinique/Clinical Neurophysiology. 2013.

5. Barin K, Dodson EE. Dizziness in the elderly. Otolaryngologic Clinics of North America. 2011;44(2):437-54.

6. Borel L, Alescio-Lautier B. Posture and cognition in the elderly: Interaction and contribution to the rehabilitation strategies. Neurophysiologie Clinique/Clinical Neurophysiology. 2014;44(1):95-107.

7. Salthouse TA. Does the level at which cognitive change occurs change with age? Psychological science. 2012;23(1):18-23.

8. Nottoli MJ. Falls Prevention. Encyclopedia of Aging and Public Health: Springer; 2008. p. 3501.

9. Stark SL, Roe CM, Grant EA, Hollingsworth H, Benzinger TL, Fagan AM, et al. Preclinical Alzheimer disease and risk of falls. Neurology. 2013;81(5):437-43.

10. Allali G, Assal F, Kressig RW, Dubost V, Herrmann FR, Beauchet O. Impact of impaired executive function on gait stability. Dementia and geriatric cognitive disorders. 2008;26(4):3649.

11. Sheridan PL, Solomont J, Kowall N, Hausdorff JM. Influence of executive function on locomotor function: divided attention increases gait variability in Alzheimer's disease. Journal of the American Geriatrics Society. 2003;51(11):1633-7.

12. Montero-Odasso M, Bergman $\mathrm{H}$, Phillips NA, Wong $\mathrm{CH}$, Sourial N, Chertkow $\mathrm{H}$. Dual-tasking and gait in people with mild cognitive impairment. The effect of working memory. BMC geriatrics. 2009;9(1):41.

13. Allali G, Dubois B, Assal F, Lallart E, de Souza LC, Bertoux M, et al. Frontotemporal dementia: pathology of gait? Movement Disorders. 2010;25(6):723-9.

14. Stuss DT, Alexander MP. Executive functions and the frontal lobes: A conceptual view. Psychological Research. 2000;63(3-4):289-98.

15. Springer S, Giladi N, Peretz C, Yogev G, Simon ES, Hausdorff JM. Dual-tasking effects on gait variability: The role of aging, falls, and executive function. Movement Disorders. 2006;21(7):950-7.

16. Hausdorff JM DG, Springer S, Yogev G, Giladi N, Simon ES. A common cognitive profile in elderly fallers and in patients with Parkinson's disease: the prominence of impaired executive function and attention. Exp Aging Res. 2006;32:411-29.

17. Springer S, Giladi N, Peretz C, Yogev G, Simon ES, Hausdorff JM. Dual-tasking effects on gait variability: The role of aging, falls, and executive function. Movement Disorders. 2006;21(7):950-7.

18. Smith-Ray RL, Hughes SL, Prohaska TR, Little DM, Jurivich DA, Hedeker D. Impact of cognitive training on balance and gait in older adults. The Journals of Gerontology Series B: Psychological Sciences and Social Sciences. 2013:gbt097. 
19. Mozolic JL, Long AB, Morgan AR, Rawley-Payne M, Laurienti PJ. A cognitive training intervention improves modality-specific attention in a randomized controlled trial of healthy older adults. Neurobiology of aging. 2011;32(4):655-68.

20. Baddeley A. Working memory, thought, and action: Oxford University Press; 2007.

21. Wollesen B, Voelcker-Rehage C, Willer J, Zech A, Mattes K. Feasibility study of dual-taskmanaging training to improve gait performance of older adults. Aging clinical and experimental research. 2015:1-9.

22. Herman T, Mirelman A, Giladi N, Schweiger A, Hausdorff JM. Executive control deficits as a prodrome to falls in healthy older adults: A prospective study linking thinking, walking, and falling. Journals of Gerontology - Series A Biological Sciences and Medical Sciences. 2010;65 $\mathrm{A}(10): 1086-92$.

23. Hausdorff JM, Yogev G, Springer S, Simon ES, Giladi N. Walking is more like catching than tapping: Gait in the elderly as a complex cognitive task. Experimental Brain Research. 2005;164(4):541-8.

24. Yogev-Seligmann G HJ, Giladi N. The role of executive function and attention in gait. Mov Disord. 2008;23:329-42.

25. Sheridan PL, Hausdorff JM. The role of higher-level cognitive function in gait: executive dysfunction contributes to fall risk in Alzheimer's disease. Dementia and geriatric cognitive disorders. 2007;24(2):125-37.

26. Smith-Ray RL, Hughes SL, Prohaska TR, Little DM, Jurivich DA, Hedeker D. Impact of cognitive training on balance and gait in older adults. Journals of Gerontology Series B: Psychological Sciences and Social Sciences. 2013;70(3):357-66.

27. Azadian E, Torbati HRT, Kakhki ARS, Farahpour N. The effect of dual task and executive training on pattern of gait in older adults with balance impairment: A Randomized controlled trial. Archives of gerontology and geriatrics. 2016;62:83-9.

28. Li KZ, Roudaia E, Lussier M, Bherer L, Leroux A, McKinley P. Benefits of cognitive dual-task training on balance performance in healthy older adults. Journals of Gerontology Series A: Biomedical Sciences and Medical Sciences. 2010;65(12):1344-52.

29. Azadian E, Taheri HR, Saberi Kakhki A, Farahpour N. Effects of Dual-Tasks on SpatialTemporal Parameters of Gait in Older Adults With Impaired Balance. Iranian Journal of Ageing. 2016;11(1):100-9.

30. Behdarvandi M. Mini-Mental State Examination. Institute of Behavioural and Cognitive Sciences, Sina. 2012.

31. Salari S, Shaeiri MR, Asghari-Moghaddam MA. Psychometric Characteristics of the Rowland Universal Dementia Assessment Scale (RUDAS) in a Sample of Iranian Elderly. Iranian Journal of Psychiatry and Clinical Psychology. 2014;20(1):74-84.

32. Remaud A, Boyas S, Caron GAR, Bilodeau M. Attentional Demands Associated With Postural Control Depend on Task Difficulty and Visual Condition. Journal of Motor Behavior. 2012;44(5):329-40.

33. de Ruiter SC, de Jonghe JF, Germans T, Ruiter JH, Jansen RW. Cognitive impairment is very common in elderly patients with syncope and unexplained falls. Journal of the American Medical Directors Association. 2017;18(5):409-13.

34. Sharma S, Mueller C, Stewart R, Veronese N, Vancampfort D, Koyanagi A, et al. Predictors of falls and fractures leading to hospitalization in people with dementia: A representative cohort study. Journal of the American Medical Directors Association. 2018.

35. Okubo Y, Schoene D, Lord SR. Step training improves reaction time, gait and balance and reduces falls in older people: a systematic review and meta-analysis. $\mathrm{Br} \mathrm{J}$ Sports Med. 2017;51(7):586-93. 
36. Taylor ME, Lord SR, Delbaere K, Kurrle SE, Mikolaizak AS, Close JC. Reaction time and postural sway modify the effect of executive function on risk of falls in older people with mild to moderate cognitive impairment. The American Journal of Geriatric Psychiatry. 2017;25(4):397406.

37. Melzer I, Kurz I, Shahar D, Levi M, Oddsson L. Application of the voluntary step execution test to identify elderly fallers. Age and ageing. 2007;36(5):532-7.

38. Schoene D, Delbaere K, Lord SR. Impaired Response Selection During Stepping Predicts Falls in Older People-A Cohort Study. Journal of the American Medical Directors Association. 2017;18(8):719-25.

39. jafari $\mathrm{m}$, SHamshiri M. Reviewing the static and dynamic balance in predicting the risk of falls in elderly people in tehran. Journal of Nursing and Midwifery Urmia University of Medical Sciences. 2015;12(11):1045-53.

40. Adkin AL, Frank JS, Carpenter MG, Peysar GW. Fear of falling modifies anticipatory postural control. Experimental brain research. 2002;143(2):160-70.

41. Melzer I, Benjuya N, Kaplanski J. Postural stability in the elderly: a comparison between fallers and non-fallers. Age and ageing. 2004;33(6):602-7.

42. Mikó I, Szerb I, Szerb A, Poor G. Effectiveness of balance training programme in reducing the frequency of falling in established osteoporotic women: a randomized controlled trial. Clinical rehabilitation. 2017;31(2):217-24.

43. Quach L, Galica AM, Jones RN, Procter-Gray E, Manor B, Hannan MT, et al. The nonlinear relationship between gait speed and falls: the maintenance of balance, independent living, intellect, and zest in the elderly of Boston study. Journal of the American Geriatrics Society. 2011;59(6):1069-73.

44. Kim JW, Eom GM, Kim CS ,Kim DH, Lee JH, Park BK, et al. Sex differences in the postural sway characteristics of young and elderly subjects during quiet natural standing. Geriatrics \& gerontology international. 2010;10(2):191-8. 